\title{
Efeitos da castração pós-natal sobre o tecido pulmonar após sepse experimental de origem abdominal em ratos $^{1}$
}

\author{
Armando José d’Acampora² ${ }^{2}$ Joel Antônio Bernhardt ${ }^{3}$, João Daniel May Serafim4, \\ Débora Cadore de Farias ${ }^{5}$, Ricardo Tramonte ${ }^{6}$
}

\begin{abstract}
d'Acampora AJ, Bernhardt JA, Serafim JDM, Farias DC, Tramonte R. Efeitos da castração pós-natal sobre o tecido pulmonar após sepse experimental de origem abdominal em ratos. Acta Cir Bras [serial online] 2004 Mar-Abr;19(2). Disponível em URL: http://www.scielo.br/acb.

Resumo - Objetivo: Avaliar os efeitos da castração pós-natal sobre o tecido pulmonar na sepse de origem abdominal induzida em ratos. Métodos: Foram utilizados 33 ratos Wistar distribuídos em dois grupos: Grupo Controle $(\mathrm{GC})=5$ machos adultos normais sem desafio séptico. Grupo Experimento (GE): 28 ratos submetidos a sepse por ligadura e perfuração de ceco (LPC) e distribuídos em três subgrupos: Subgrupo Macho (SgM): nove ratos machos adultos, sem castracão e submetidos a sepse por LPC. Subgrupo Fêmea (SgF): nove ratos fêmeas adultos normais submetidas a sepse por LPC. Subgrupo Castrado $(\mathrm{SgC})$ : dez ratos machos que no quarto dia de vida foram submetidos a orquiectomia bilateral e quando adultos à sepse por LPC. Após a LPC os animais foram observados até o óbito, realizada análise histomorfométrica do pulmão, observando-se o número de polimorfonucleares e mononucleares. Resultados: $50 \%$ dos animais do $\mathrm{SgC}$ sobreviveram 24 horas, contra $33 \%$ do $\mathrm{SgF}$ e $0 \%$ do SgM, mostrando uma nítida influência da castração na resposta ao desafio séptico. O número de polimorfonucleares e mononucleares não foi diferente estatisticamente entre o SgC e CG, estando estatisticamente aumentados no SgM e SgF. Conclusão: Os animais castrados apresentaram uma maior tendência à sobrevida e menor alteração pulmonar.
\end{abstract}

DESCRITORES - Castração. Pulmão. Peritonite. Sepse. Ratos.

\section{Introdução}

A sepse de origem bacteriana continua com alta taxa de morbidade e de mortalidade. ${ }^{1}$ A sepse pode ser o evento final de um paciente em estado avançado de doença grave, como também é causa comum e potencialmente prevenível de morte em pacientes com doenças menos severas. ${ }^{2}$ A literatura mostra taxa de mortalidade nos pacientes vítimas de sepse abdominal oscilando entre 20 a $80 \%{ }^{3,4}$ A ampla faixa de variação entre os índices de mortalidade encontrada nos trabalhos, reflete a diferença de padronização nos parâmetros de observação da sepse. ${ }^{1}$
Tudo indica que os eventos que decorrem da sepse e do choque séptico são causados por endotoxinas produzidas por bacilos Gram negativos, com ação direta sobre as células, causando lesão ou alterando suas funções, ou ainda por ação indireta, aparentemente, mais importante, deflagrando a síntese, liberação ou ativação da cascata de mediadores derivados das células do hospedeiro ${ }^{5,6,7,8}$, pois os polimorfonucleares são as células mais numerosas na resposta aguda a sepse. ${ }^{9,10}$ Quando o processo inflamatório é intenso, ocorre lesão endotelial com aumento da permeabilidade capilar e edema, que leva a oclusão capilar e isquemia ${ }^{5,8,11,12,13}$, sugerindo que a maior ameaça à sobrevida após a sepse não decorre da infecção propriamente dita, mas sim da progressiva disfunção dos órgãos, como consequiência de uma resposta inflamatória sistêmica. ${ }^{14,15}$ Aparentemente o pulmão é o primeiro órgão a ser atingido. ${ }^{1,9,10,13}$

Mihmanli e col. ${ }^{16}$, empregando modelo de sepse após perfuração do ceco de ratos, demonstra após estudo histopatológico do pulmão que ocorre uma proliferação acentuada de polimorfonucleares no tecido pulmonar, suguerindo que a aplicação de antibióticos de amplo expectro podem prevenir a translocação bacteriana provocada pela sepse de origem abdominal, bem

1. Trabalho do Núcleo de Pesquisa da Disciplina de Técnica Operatória e Cirurgia Experimental da Universidade Federal de Santa Catarina (TOCEUFSC).

2. Professor Adjunto, Doutor em Técnica Operatória e Cirurgia Experimental pela Universidade do Estado de São Paulo - Escola Paulista de Medicina (UNIFESP-EPM), Líder do Grupo de Pesquisa TOCE-UFSC.

3. Mestrando do Curso de Pós-Graduação em Ciências Médicas da UFSC.

4. Aluno do Curso de Graduação em Medicina da UFSC.

5. Aluna do Curso de Graduação em Medicina da UFSC.

6. Professor Adjunto, Doutor em Histologia do Núcleo de Pesquisa da TOCE-UFSC. 
como alterar a taxa de sobrevivência destes animais após o choque séptico.

Na resposta a sepse, estudos experimentais, clínicos e epidemiológicos, sugerem uma diferença sexual na susceptibilidade da resposta inflamatória sistêmica. 1, 17,18, 19 Oberholzer e col. ${ }^{18}$ mostraram que as mulheres possuem um risco menor de desenvolver sepse e disfunção de múltiplos órgãos e sistemas comparados aos homens, quando submetidos a uma lesão grave.

Schroder e col..$^{19}$, em 1998, confirmaram que existe diferença sexual na sepse humana, sendo que as mulheres possuem um melhor prognóstico, e que este fato deve estar relacionado com o aumento dos níveis de mediadores antiinflamatórios no sexo feminino.

Em recentes estudos sobre sepse experimental em ratos Wistar, d'Acampora e col. ${ }^{1}$ observaram que as fêmeas são mais resistentes à infecção que os machos, evoluindo com menor freqüência para o óbito.

Parece que a provável explicação para o fato, sejam alterações sofridas durante o desenvolvimento do eixo HipotálamoHipófise-Adrenal (HPA) que sofre influência de núcleos hipotalâmicos sexualmente diferenciados, sendo capazes de alterar a resposta imune induzida experimentalmente. ${ }^{17,20,21} \mathrm{O}$ sistema imune também sofre influências diretas do sistema endócrino. Estudos recentes mostram que as células T e B são alvos da ação dos hormônios sexuais ${ }^{20,21,22}$. A testosterona possui atuação nas células $\mathrm{T}$ e interfere no sinal necessário para a célula $\mathrm{B}$ produzir anticorpos, diminuindo a sua produção ${ }^{27}$. Já o estrogênio tem a capacidade de aumentar a capacidade dos macrófagos e monócitos de fagocitarem antígenos ${ }^{22}$. É descrito na literatura pesquisada que ratos machos castrados aumentam os níveis de $\operatorname{IgM}$ e IgG na resposta imune quando comparados aos não castrados, e que níveis de IgM estão relacionados com o número de cromossomos $\mathrm{X}$ existentes 22, 23, 24. Os níveis de $\operatorname{IgM}$, IgG e IgA são maior nas fêmeas que nos machos ${ }^{23}$.

Apesar de diversos trabalhos na literatura indicarem a existência de dimorfismo sexual na resposta imune entre mamíferos, não foi possível encontrar nas referências consultadas nenhum trabalho que utilizasse ratos machos castrados durante o período crítico de diferenciação sexual do Sistema Nervoso Central (primeira semana de vida pós-natal) para analisar os efeitos desta castração sobre o tecido pulmonar em resposta a um desafio séptico quando estes animais atingissem a idade adulta. Portanto o objetivo primário deste trabalho foi o de analisar os efeitos desta castração pós-natal sobre a histologia do pulmão destes animais após um desafio séptico na idade adulta.

\section{Métodos}

Foram utilizados 33 (trinta e três) ratos da espécie Rattus norvergicus da linhagem Wistar, mantidos em gaiolas plásticas com acesso livre a alimentação e água, e mantendo o ciclo dia e noite. Os animais foram distribuídos em dois grupos:

1. Grupo controle - GC ( $n=5)$ : cinco animais do sexo masculino, que foram submetidos à eutanásia para a obtenção do lobo inferior do pulmão direito para avaliação morfométrica do pulmão normal.

2. Grupo experimento-GE ( $n=28)$ : Os animais deste grupo foram distribuídos em 3 subgrupos conforme descrito a seguir:

2.1. Subgrupo macho - $\operatorname{SgM}(\mathrm{n}=9)$ : nove animais do sexo masculino.

2.2. Subgrupo fêmea - $S g F(n=9)$ : nove animais do sexo feminino.

2.3. Subgrupo castrado $-S g C(\mathrm{n}=10)$ : $\mathrm{dez}$ animais do sexo masculino que no $4^{\circ}$ dia de vida foram submetidos à orquiectomia bilateral.

Os animais do $\mathrm{SgC}$ no quarto dia foram submetidos à anestesia geral através da inalação de éter etílico, após serem anestesiados foram posicionados em decúbito dorsal sobre a base do microscópio cirúrgico. Após ser realizada a anti-sepsia da parede ventral do abdome com iodopovidona, foram realizadas duas incisões para-medianas de $5 \mathrm{~mm}$ abaixo da cicatriz umbilical, através das quais foram exteriorizadas as gônadas, ligadura da artéria testicular juntamente com o ducto deferente com fio de poligalactina 6-0 e a secção dos testículos e epidídimo de ambos lados. A parede abdominal e a pele foram suturadas com pontos totais com fio de poligalactina 6-0.

Quando os animais do GE apresentavam peso entre 180 e $240 \mathrm{~g}$, foram anestesiados com éter etílico sob campânula e realizada uma laparotomia mediana de aproximadamente $3 \mathrm{~cm}$. Exposto o ceco, procedeu-se a ligadura do colo ascendente na porção mais proximal com fio de algodão 3-0 e realização uma incisão de $5 \mathrm{~mm}$ na porção avascular. A síntese da cavidade abdominal foi realizada por planos com fio de nylon 5-0. Após a cirurgia, os animais foram colocados isolados em gaiolas plásticas, com acesso livre a água e alimentação própria para a espécie, sendo os mesmos acompanhados até o momento do óbito por um período máximo de 24 horas, observando o tempo de sobrevida do animal após a perfuração do ceco. Dos cinco primeiros animais de cada subgrupo do grupo experimento que evoluíram para o óbito, e dos cinco animais do GC que foram submetidos à eutanásia através de inalação de éter etílico sob campânula, retiraramse o lobo inferior do pulmão direito, fixados em formol a $10 \%$, incluídos em parafina e seccionados em cortes de 10 mm. As lâminas obtidas foram coradas pela hematoxilina e eosina, e submetidas à análise morfométrica, com auxilio de uma grade ocular de contagem, sob um aumento de 400x, onde se contava o número de polimorfonucleares e mononucleares numa área de 100 x $100 \mathrm{~mm}$, delimitada pela grade ocular, que tangenciava um bronquíolo (Figura 1).

Os resultados obtidos foram submetidos à análise estatística. Para a comparação do tempo de sobrevida dos animais foi utilizando a curva de sobrevida de KAPLAN-MEIER. Já para a análise dos achados morfométricos foi utilizado o teste estatístico ANOVA modificado por NEWMAN-KEULS, sendo considerados estatisticamente significantes para um $\mathrm{p}$ $£ 0,05$.

\section{Resultados}

Dos 28 animais do grupo experimento, 20 evoluíram para o óbito em até 24 horas após a indução da sepse. A curva de sobrevida de KAPLAN-MEIER dos animais do GE encontra-se na Figura 2.

No SgM, todos os animais evoluíram para óbito nas 24 horas após a indução da sepse, no $\mathrm{SgF}$ três animais sobreviveram até a $24^{\text {a }}$ hora perfazendo um total de $33,3 \%$ dos animais deste subgrupo. Já no $\mathrm{SgC}$ $50 \%$ dos animais sobreviveram as primeiras 24 horas. 


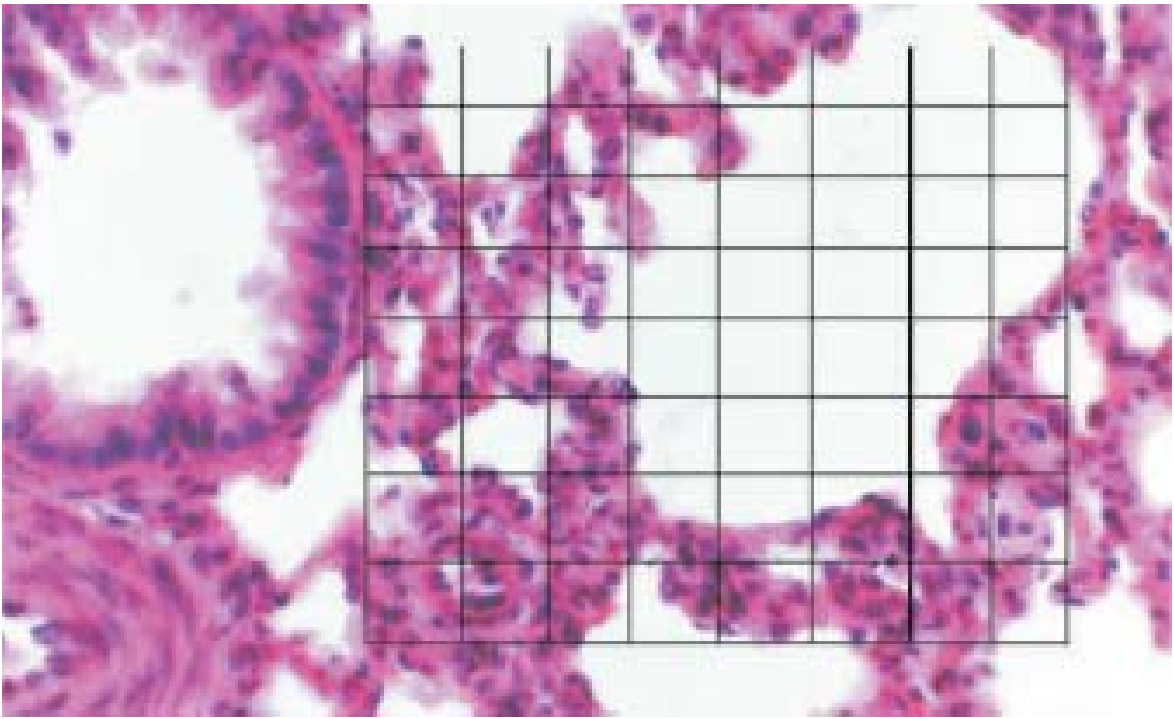

FIGURA 1 - Fotomicrografia com aumento de 400x, ilustrando como foi realizada a contagem celular com ajuda da grade ocular.

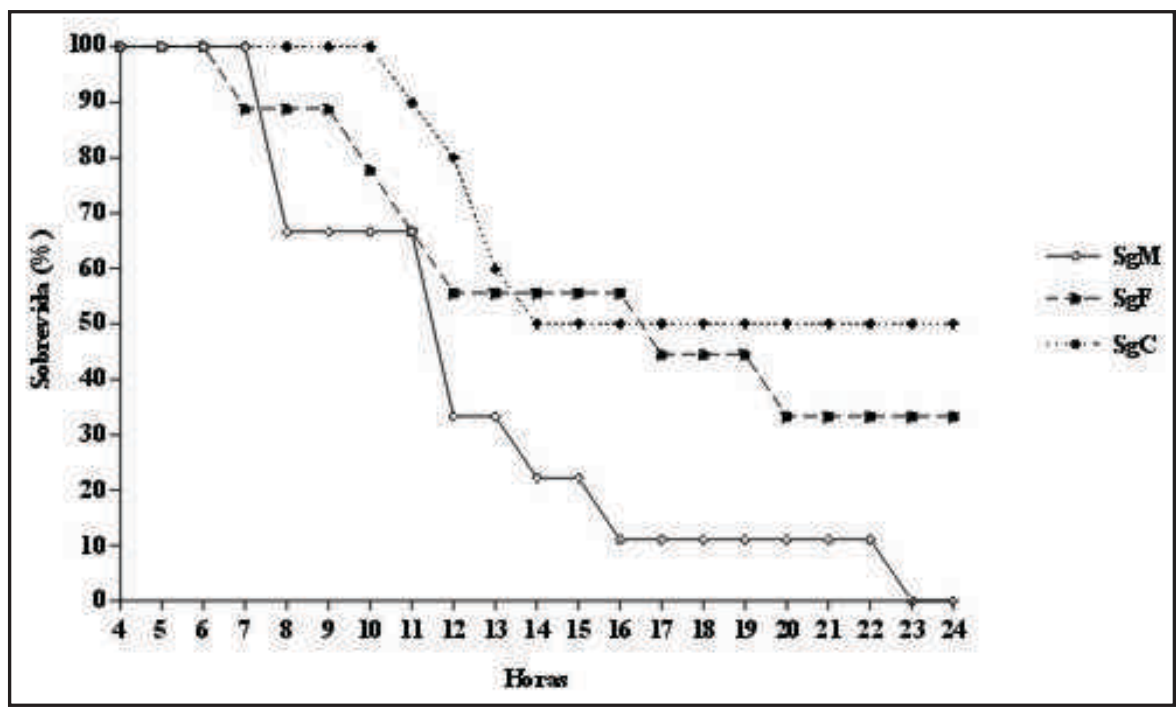

FIGURA 2 - Curva de KAPLAN-MEIER de sobrevida em 24 dos animais estudados conforme o seu subgrupo.

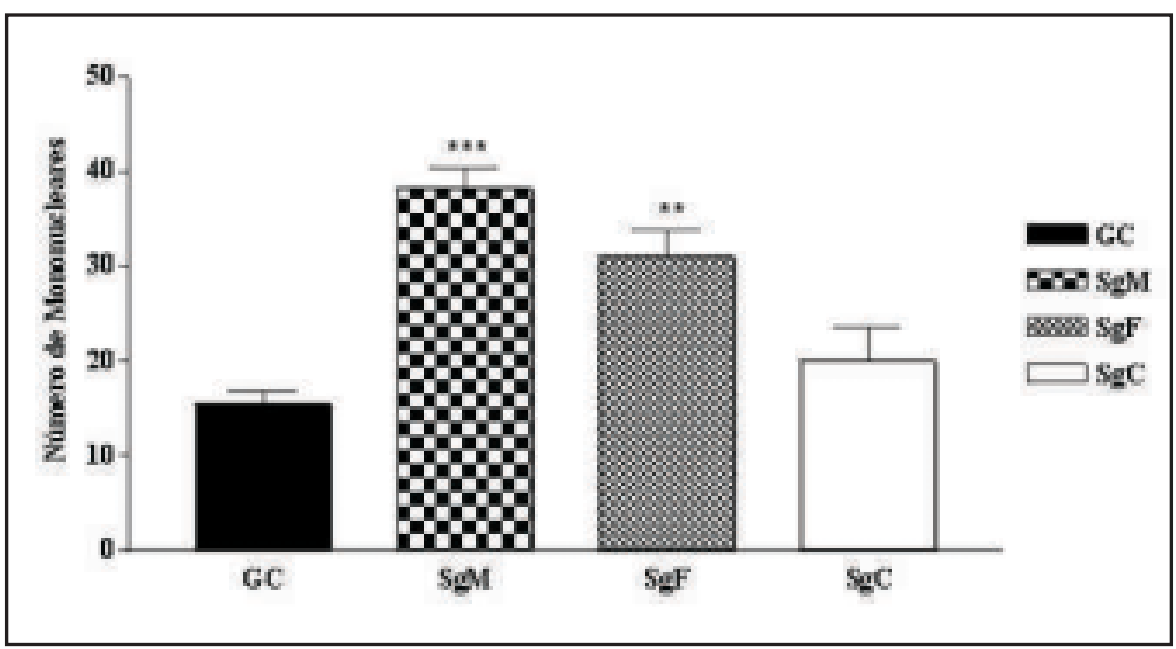

FIGURA 3 - Número de mononucleares no pulmão dos ratos Wistar em estudos conforme o grupo.

LEGENDA: $* *=\mathrm{p} £ 0,01$ e $* * *=\mathrm{p} £ 0,001$, quando comparado com o GC.
Utilizando o teste estatístico ANOVA complementado com NEWMAN-KEULS, na avaliação dos mononucleares, observamos que existe uma diferença estatística entre o GC e o $\operatorname{SgM}(\mathrm{p}<0,001)$, entre o GC e o $\operatorname{SgF}(\mathrm{p}<0,01)$ e não havendo diferença estatisticamente significante entre o GC e o $\mathrm{SgC}$.

Comparando os subgrupos do grupo experimento entre si, observamos que há uma diferença estatisticamente significante entre os $\mathrm{SgM}$ e $\mathrm{SgC}(\mathrm{p}<0,001)$ e entre os $\mathrm{SgF}$ e $\mathrm{SgC}(\mathrm{p}<0,01)$. Entre os $\mathrm{SgMe} \mathrm{SgF}$ não houve diferença estatística (Figura 3). Analisando a média dos polimorfonucleares entre os diferentes grupos, observamos que há diferença estatística entre o $\mathrm{GC}$ e $\mathrm{SgM}$ e entre o GC e o $\mathrm{SgF}$ (ambos p $<0,05$ ). Já entre os demais grupos não observamos diferença estatisticamente significante (Figura 4).

\section{Discussão}

O problema, sepse de origem abdominal, é freqüente na prática médica, sendo amplamente discutido sem que se tenha chegado a um consenso. ${ }^{1}$

O modelo experimental é um dos principais meios para a resolução destes tópicos conflitantes sobre a sepse de origem abdominal. Acredita-se que o modelo experimental é o único método de estudo em que é possível avaliar e controlar os fenômenos sépticos desde a sua instalação até o momento de falência dos órgãos e sistemas, podendo-se interferir de diferentes formas e em diferentes tempos neste processo. ${ }^{1}$

Otero-Anton e col..$^{25}$ relatam que a ligadura e perfuração do ceco com incisão de $5 \mathrm{~mm}$ leva a uma mortalidade maior que $80 \%$ em 24 horas, e que em apenas 5 horas após a perfuração há hemocultura positiva, isolando bactérias do trato digestivo.

No entanto, vários trabalhos, tanto experimentais como clínicos, têm demonstrado que as fêmeas são mais resistentes a sepse que os machos, apresentando uma maior sobrevida ${ }^{1,18,}{ }^{19}$.Assim observamos:

Zellweger e col. ${ }^{26}$ observaram que após sepse de origem polimicrobiana em ratos, a mortalidade era maior nos ratos machos, Bäuerle e col. ${ }^{27}$ observaram que as mulheres são menos susceptíveis e tem um melhor prognóstico na sepse, Schröder e col. ${ }^{19}$ mostraram que a taxa de sobrevida para 
as mulheres era maior que a dos homens na sepse, e Wichmann e col. ${ }^{28}$ que também observaram que um número significativamente menor de mulheres necessita de cuidados intensivos após cirurgia, e que há uma menor incidência de sepse e choque séptico em mulheres do que em homens quando submetidos a cuidados intensivos, porém não observaram uma diferença na mortalidade entre ambos os sexos quando desenvolviam sepse aguda. Observou-se, no decorrer deste experimento que os animais do SgF têm uma tendência maior a sobrevida que os do SgM.

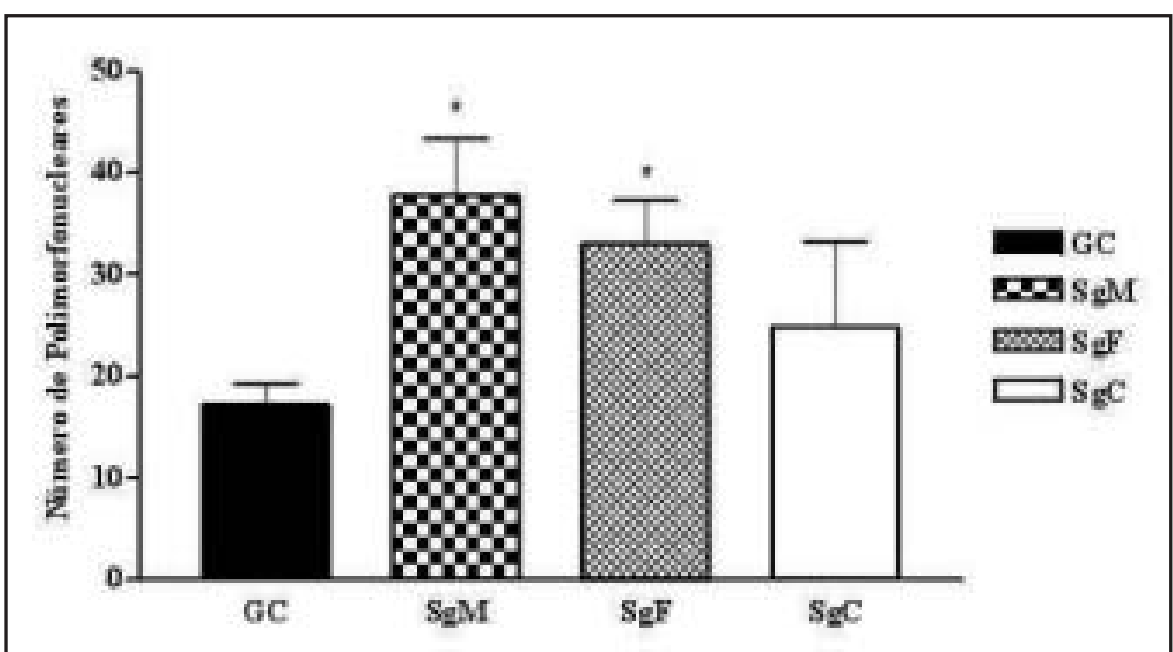

FIGURA 4 - Número de polimorfonucleares no pulmão dos ratos Wistar em estudos conforme o grupo.

LEGENDA: * $=$ p $£ 0,05$, quando comparado com o GC.

Em 1996, Wichmann e col. ${ }^{30}$ mostraram que a castração de ratos machos antes de choque hemorrágico previne a depressão da função imune mediada por células, mostrando um efeito benéfico na depleção de testosterona sobre a função imune celular após choque hemorrágico, concluindo que a manutenção da imunidade nos animais castrados após choque hemorrágico pode ter relação com a deficiência de testosterona.

Observamos que os animais castrados apresentaram a maior sobrevida à sepse nas primeiras 24 horas, sendo que tal fato seja devido a diminuição do nível da testosterona plasmática.

Pine e col. ${ }^{31} \mathrm{em}$ estudo observando o mau funcionamento orgânico e a morte de pacientes com sepse de origem abdominal, observaram que $28 \%$ dos pacientes que desenvolveram sepse apresentaram mau funcionamento pulmonar, sendo o pulmão
Duscan e col. ${ }^{29}$ ao estudarem os efeitos histopatológicos de diferentes tratamentos no tecido pulmonar de camundongos pré-tratados com antibióticos e esteróides e um modelo de sepse provocada por $\underline{\text { E.coli }}$, demonstraram que a inflamação peribronquiolar estava significantemente aumentada nos animais que receberam tratamento por esteróides. Seus dados são compatíveis com os resultados observados em nosso experimento, indicando que os esteróides acentuam a resposta inflamatória no tecido pulmonar em animais adultos.

\section{o órgão mais afetado, e que $63 \%$ destes evoluíram para a morte.}

Segundo Runcie e col..$^{32}$ o dano pulmonar provocado após infecção abdominal é causado por contribuições de leucócitos, plaquetas, microêmbolos, influências neurológica, sistema complemento, citocinas e radicais livres. A adesão de neutrófilos nos capilares pulmonares é um importante mecanismo no dano pulmonar. Refere também que o dano pulmonar pode ser limitado pela neutropenia.

Observou-se que os animais dos SgM e SgF apresentaram um número significativamente maior de mononucleares quando comparado ao GC, e que o SgC não apresentou uma diferença estatística destas células comparando com o GC. Também observamos que houve uma diferença estatisticamente significante quando comparando os SgM e SgF com o SgC, sendo o número de mononucleares maior nos 2 primeiros subgrupos. Assim observamos que o $\mathrm{SgC}$ apresentou-se mais semelhante ao GC neste aspecto.

Analisando os polimorfonucleares, vimos que o $\mathrm{SgM}$ e o SgF apresentaram um número estatisticamente maior quando comparado ao GC. Quando comparando o SgC com o GC não houve diferença estatística significante.

Com isto, observamos que em relação à análise morfométrica realizada nos pulmões, o SgC ficou mais próximo ao GC, e que o SgC também apresentou maior sobrevida, sendo que este aumento na sobrevida pode estar relacionada com a menor quantidade de leucócitos no pulmão, assim levando a um menor dano pulmonar, quando comparados a trabalhos anteriores onde não houve castração. ${ }^{1,9,10,13,33}$

\section{Conclusão}

Os animais submetidos à castração pósnatal, apresentaram uma maior tendência a sobrevida e menor alteração pulmonar, após a indução da sepse por ligadura e perfuração de ceco.

\section{Referências}

1. d'Acampora AJ. Avaliação histológica da sepse experimental em ratos Wistar [Tese Doutorado]. Universidade Federal de São Paulo - Escola Paulista de Medicina; 1996.

2. Harris RL, Musher DM, Bloom K, Gathe J, Rice L, Sugarman B, Williams TW, Young EJ. Manifestatios of Sepsis. Arch. Intern. Med 1987; 147: 1987-95.

3. Steinberg D. On leaving the peritoneal cavity open in acute generalized suppurative peritonitis. Am J Surg 1979; 137: 216-20.

4. McCauley RD, Heel KA, Christiansen KJ, Hall JC. The effect of minimum luminal nutrition on bacterial translocation and atrophy of the jejunum during parenteral nutrition. J. Gastroenterol Hepatol 1996; 11(1): 65-70.

5. Fein AM, Calalang-Colucci MG. Acute lung injury and acute respiratory distress syndrome in sepis and septic shock, Critcal Care Clinics 2000; 16(2): 289-317.

6. Christou NV. Sistemic and peritoneal host defense in peritonitis. World J Surg 1990; 14:184-90.

7. Meng XJ, Song XH, Li L, Li H. Organassociation phenomena during sepse. TNF and IL-6 in different macrophages. Chin Med J 1993; 106:458:62.

8. Parker MM, Parrillo JE. Septic Shock Hemodynamics and Pathogenesis, JAMA 1983; 250(24): 3324-7.

9. Gerent MM, d'Acampora AJ, Souza JL, Aqel MN, Aust JR, Guesser L. Estudo histológico do pulmão de ratos em sepse de origem abdominal. Livro de resumos do $6^{\circ}$ Congresso Brasileiro de Ciência de Animais de Laboratório, 1998; 1: 39-40. 
10. d’Acampora AJ, Tramonte R, Carvalho ROM, Ortellado DK, Serafim JDM. Pulmão e Peritônio após Sepse Experimental de Origem Abdominal em Ratos Wistar. Revista do Colégio Brasileiro de Cirurgiões 2001; 28 (Supl 1): 276.

11. Cotran RS, Kumar V, Robbins SL. Robbins Pathologic basis of disesase. 5. ed. Philadelphia, Saunders, 1994. 1400 p.

12. Bonin GS, d'Acampora AJ, Matte ELA, Suoza JL, Albuquerque MM, Silva MT, Ortellado DK, Carvalho ROM, Damas TB, Serafim JDM. Repercussão Histopatológica Renal da Sepse Experimental Tratada com Gentamicina. 2000; Annais da XXXIV Jornada Catarinense de Debates Científicos e Estudos Médicos.

13. Aqel M. Estudo Histológico de Pulmão de Ratos após Sepse Experimental de Origem Abdominal [Monografia de Conclusão de Curso]. Florianópolis: Universidade Federal de Santa Catarina; 1996. 46p

14. Wakefield CH, Barclay GR, Fearon KC, Goldie AS, Ross JA, Grant IS, et al. Proinflammatory mediator activity, endogenous antagonists and the systemic inflammatory response in intra-abdominal sepsis. Br J Surg 1998; 85 (6):818-25

15. Welt-Wolf KE, Carraway MS, Huang YC, Simonson SG, Kantrow SP, Piantadosi CA. Bacterial priming increases lung injury in gram-negative sepsis. Am. J. Respir Crit Care Med 1998; 158(2): 610-9.

16. Mihmanli A, Tahaoglu K, Sahin I, Agca B, Kalyoncu A, Tuncer F, Sakiz D. The effect of antibiotic terapy on lung pathology in experimental models of sepsis. Ulus Travma Derg, 2000; 8(1):3-5.

17. Serafim JDM, Nova ML, Tramonte R, Bernhardt JÁ, Xikota JC, Fröde TS, d'Acampora AJ. Dimorfismo sexual na resposta a sepse - Revisão Bibliografica. Anais do XI Seminário de Iniciação Científica 2002; 1:465.

18. Oberholzer A, Kell M, Zellweger R, Steckholzer U, Trentz O, Ertel W. Incidence of septic complications and multiple organ failure in severely injured patients is sex specific. Journal of Trauma 2000; 48 (5): 932-7.

19. Schröder J, KahlkeV, Staubach KH, Zabel P, Stüber F. Gender differences in human sepsis, Arch Surg 1998; 133: 1200-5.

20. Haas HS, Schauenstein K. Neuroimmunomodulation via limbic structures - The neuroanatomy of psychoimmunology. Progress in Neurobiology 1997; 51: 195-222.

21. Sanks N, McCormick CM, Meaney MJ. Sex differences in hypothalamic-pituitaryadrenal responding to endotoxin challenge in the neonate: reversal by gonadectomy. Develop. Brain Research 1994; 79:260-6.

22. Ahmed SA, Penhale WJ, Talal N. Sex hormones, immune responses, and autoimmune diseases - Mechanisms of sex hormone action. AJP 1985; 531-51.

23. Schuurs AHWM, Verheul, HAM. Effects of gender and sex steroids on the immune response. J. Steroid Biochem. 1990; 35(2) 157-72.

24. Golsteyn E, Fritzler MJ. Review: The role of thymus-hypothalamus-pituitary-gonadal axis in normal immune processes and autoimmunity. The J. of Rheumatology 1987; 14(5): 982-90.

25. Otero-Antón E, González-Quintela A, López-Soto A, López-Ben S, Llovo J, Pérez LF. Cecal Ligation and Puncture as a Mode of Sepsis in the Rat: Influence of the Puncture Size on Mortality, Bacteremia, Endotoxemia and Tumor Necrosis Factor Alpha Levels. European Surgical Reserch $2001 ; 33$ (2): 77-9.
26. Zellweger R, Wichmann MW, Ayala A, Stein $\mathrm{S}$ DeMaso C, Chaudry I. Females in proestrusstate maintain splenic immune functions and tolerate sepsis better tha males. Crit Care Med 1997; 25(1): 106-10.

27. Bäuerle R, Rücker A, Schmandra TC, Holzer K, Encke A, Hanisch E. Markov Cohort simulation study reveals evidence for sexbased difference in Intensive Care Unit patients. Am J Surg 2000; 179:207-11.

28. Wichmann MW, Zellweger R, DeMaso CM, Ayala A, Chaudry IH. Enhace immune responses in fameles. As opposed to decresed responses im males following hemorrhagic shock and resuscitation. Cytokines 1996 8(11): 853-63.

29. Duzcan E; Bakir M; Dokmetas I; Dogonay M; Gunes H. The histopathological effects of different treatments on lung tissue of mice pretreated wiht cyclophosphamide and steroids in experimental E. coli sepsis. Mikrobiyol Bul 1991.

30. Wichmann MW, Zellweger R, DeMaso CM, Ayala A, Chaudry IH. Mechanism of Immunosupression in males following trauma-hemorrhage - Critical role of testosterone. Arch Surg 1996; 131: 1186-92.

31. Pine RW, Wertz MJ, Lennard ES, Dellinger EP, Carrico CJ, Minshew BH. Determinants of organ malfunction or death in patients with intra-abdominal sepsis: a discriminant analysis. Arch Surg 1983; 118: 242-8.

32. Runcie MB, Ramsay G. Intraabdominal Infection: pulmonary failure. World $\mathrm{J}$ of Surg 1990; 14: 196-203.

33. Tramonte, R, Carvalho, ROM, Ortellado, DK, Serafim, JDM, Dambrós, JM, d'Acampora, AJ. Análise morfométrica de Pulmão e Peritônio de ratos, após sepse experimental de origem abdominal. Anais da XXXIV Jornada Catarinense de Debates Científicos e Estudos Médicos, 2000,

d'Acampora AJ, Bernhardt JA, Serafim JDM, Farias DC, Tramonte R. The effect of post-natal castration in pulmonary tissue after experimental abdominal sepsis. Acta Cir Bras [serial online] 2004 Mar-Apr;19(2). Available from URL: http://www.scielo.br/ acb.

ABSTRACT - Purpose: Analyse the effects of post-natal castration in the pulmonary response during inducible sepsis in rats. Methods: Thirdy tree rats (Wistar) were separated in two groups: Control group (GC): five adults males rats in order to analyse the normal lungs; and Experimental group (GE): twenty eight rats submited to sepsis by ligature and perfuration of the cecum (LPC) divided in tree sub-groups: Males (SgM) nine males rats submited to sepsis by LPC, Females ( $\mathrm{SgF}$ ) nine female rats submited to sepsis by LPC, and Castration (SgC) ten males rats castrated in the $4^{\circ}$ day after birth, and submited by sepsis in adult age using LPC. After LPC, all animals were observed until death. A fragment of the right lung in all animals was submited to histologic and morphometric analysis to evaluated the number of polymorphonuclear and mononuclear cells. Results: $50 \%$ of the rats in the $\mathrm{SgC}$ have a survive time of $24 \mathrm{hs}$, against $33 \%$ of the animals in the $\mathrm{SgF}$ and $0 \%$ in the $\mathrm{SgM}$. The number of polymorphonuclear cells and mononuclear cells in the lung in SgC and GC, shows no statistic differences, but in animals of SgM and $\mathrm{SgF}$ groups, we found an increase of these cells with significant statistic differences. Conclusion: Rats in the $\mathrm{SgC}$ shows a increase of survival time after LPC and the least alterations in the lung observed.

KEY WORDS - Castration. Lung. Abdominal Sepsis. Rats.

Conflito de interesse: nenhum

Correspondência: Fonte de financiamento: nenhuma

Armando José d'Acampora

Condomínio San Diego, casa 9

Parque São Jorge - Itacorubi

88034-420 Florianópolis - SC

acampora@ccs.ufsc.br

Data do recebimento: 04/12/2003

Data da revisão: 08/01/2004

*Foto colorida disponível em www.scielo.br/acb.

Data da aprovação: 30/01/2004 